\title{
O estágio supervisionado de inglês como lugar de conflitos para o desenvolvimento conceitual e identitário docente
}

\author{
Nadia Karina Ruhmke-Ramos* \\ Renata Gomes Luis**
}

\begin{abstract}
Resumo:
Neste trabalho, analisamos dados de duas pesquisas qualitativas na área de formação inicial de professores de inglês (LUIS, 2017; RUHMKE-RAMOS, 2018) realizadas no mesmo contexto, com o objetivo de identificar os pontos comuns entre os estudos. Os dados indicaram que esta etapa da formação é marcada por conflitos surgidos a partir da desestabilização tanto de conceitos (VYGOTSKY, 1987) sobre ensino-aprendizagem de inglês quanto de identidades profissionais em (re)construção (WENGER, 1998). Tais conflitos se deram principalmente em relação ao gerenciamento de sala de aula e a análise indicou que a mediação dos conflitos pareceu oportunizar transformações na prática pedagógica e na identidade das alunas-professoras ao longo do processo. Além disso, observamos a importância do diálogo entre pesquisas com perspectivas diferentes para uma compreensão mais ampla dos contextos investigados.
\end{abstract}

\section{Palavras-chave:}

Estágio supervisionado de inglês. Conflitos. Desenvolvimento conceitual. (Re)construção de identidade docente.

\begin{abstract}
:
This work analyses data from two qualitative studies in the area of pre-service teacher education (LUIS, 2017; RUHMKE-RAMOS, 2018) carried out in the same context, with the objective of identifying commonalities between the studies. The data suggested that this education period is immersed in conflicts that emerge from the destabilization of concepts (VYGOTSKY, 1987) related to English teaching and learning as well as (re)construction of professional identities (WENGER, 1998). Such conflicts were mostly related to classroom management and the analysis indicated that the mediation of such conflicts suggested opportunities of transformation in the pedagogical practices and in the identity of student-teachers in the process. In addition, we state the importance of dialogue between research from different perspectives in order to broaden the understanding of the investigated contexts.
\end{abstract}

\section{Keywords:}

Practice teaching. Conflicts. Conceptual development. (Re)construction of professional teacher identity.

\footnotetext{
*Doutora em Letras - Inglês pela Universidade Federal de Santa Catarina. E-mail: nadiakrramos@gmail.com. ORCID iD: http://orcid.org/0000-0002-2674-8442.

** Doutora em Estudos Linguísticos pela Universidade Federal de Santa Catarina e professora do Colégio de Aplicação UFSC. E-mail: renata.gomes.luis1@gmail.com. ORCID iD: https://orcid.org/0000-0002-6530-3905.
} 


\section{Introdução}

O presente artigo procura discutir resultados de duas pesquisas qualitativas de cunho etnográfico de doutorado na área de formação de professores (LUIS, 2017; RUHMKE-RAMOS, 2018) que, através de olhares diferentes sobre o processo de formação inicial durante o estágio supervisionado de inglês, identificou aspectos comuns em ambos os estudos. Um dos conceitos em comum às pesquisas foi o entendimento desta etapa da formação des alunes-professores ${ }^{1}$ como marcada por conflitos surgidos a partir da desestabilização tanto de conceitos (VYGOTSKY, 1987) sobre ensino-aprendizagem de línguas quanto de identidades profissionais em (re)construção (WENGER, 1998).

Ao termos a oportunidade de acompanhar es alunes-professores ao longo de um ano letivo, pudemos traçar o desenvolvimento conceitual pelo qual eles passaram. Desenvolvimento este que se dá no conflito entre os conceitos espontâneos que constituem o repertório desses alunes-professores, suas identidades profissionais e desafios apresentados durante o estágio. As situações de conflitos são complexas e não envolvem somente o desenvolvimento cognitivo, mas também a transformação identitária deste futuro profissional.

\section{Revisão de literatura}

O estágio curricular obrigatório é um espaço propício aos tensionamentos que envolvem não somente es alunes-professores, mas a universidade e a escola como discutido em Wielewicki e Ruhmke-Ramos (2020). Es autores refletem sobre a construção do trabalho colaborativo entre a universidade e escola, processo esse também cheio de desafios, que iniciou no Colégio de Aplicação da UFSC há mais de 20 anos (LUCENA; SILVA; BAZZO, 2014). Os moldes nos quais o estágio supervisionado de inglês acontece proporciona a es participantes (alunes-professores do curso de Letras-Inglês da UFSC; professores formadores da universidade e da escola) oportunidades de desenvolvimento conceitual e de aprenderem manufaturando comunidades de prática de professores.

\section{A construção da identidade profissional em comunidades de prática}

De acordo com Lave e Wenger (1991) aprender é um aspecto da prática social que denota nossa participação em comunidades de prática. Esses autores explicam que quando os aprendizes são novatos nas práticas da comunidade à qual desejam pertencer, eles têm uma posição periférica na comunidade. Entretanto, na medida em que os veteranos vão possibilitando o acesso deles às práticas da comunidade, eles podem se mover em direção à mais participação, à participação completa e finalmente ao aprendizado. O resultado desse engajamento ativo dos participantes em comunidades de prática é tanto a aprendizagem quanto a construção de identidades para eles, pois como Lave e Wenger (1991) argumentam "aprender implica tornar-se um participante completo, um membro, um tipo de pessoa" (p. 53). Em publicação posterior, Wenger (1998) acrescenta à discussão o papel preponderante dos conflitos no âmbito das comunidades de prática, inclusive sua importância no próprio processo de aprendizagem. São a esses conflitos e desestabilizações que nos debruçaremos a seguir².

\footnotetext{
1. No intuito de adotar uma perspectiva mais inclusiva, optamos pela substituição do gênero binário masculino (O)/feminino (A), pelo gênero neutro E. Exemplo: ao invés de usarmos alunos ou alunas, utilizamos alunes. Entendemos que é uma abordagem relativamente nova em textos acadêmicos e por isso, sugerimos a leitura de um texto que aborda essa linguagem no contexto das redes online e que apresenta mais exemplos de uso do gênero neutro: MOKWA, Marcela. O papel e a função da linguagem não binária ou neutral no contexto das redes online: sobre as evidências da linguagem neutra em contextos cibernéticos e sociais. Revista Movimento, São Paulo, 28 fev. 2019. Disponível em: https://movimentorevista.com.br/2019/02/o-papel-e-a-funcao-da-linguagem-nao-binaria-ou-neutral-no-contexto-das-redes-online/. Acesso em: 19 jun. 2020.

2. Para uma análise mais detalhada do papel dos conflitos em comunidades de práticas, ver Handley, Sturdy, Fincham e Clark (2006) e Halu (2010).
} 


\section{Os conflitos inerentes às comunidades de prática e seu papel}

Lave e Wenger (1991) já haviam mencionado os conflitos que podem ocorrer principalmente entre veteranes e novates da comunidade a partir do movimento des novates em direção a mais participação nas práticas da comunidade. Segundo eles, es novates precisam lidar com o seguinte dilema: eles precisam se engajar nas práticas que já existem, entendê-las e participar delas para se tornarem membres da comunidade, mas ao mesmo tempo, eles têm um lugar e interesse em seu desenvolvimento já que eles começam a estabelecer sua própria identidade no futuro da comunidade (LAVE; WENGER, 1991, p. 115).

Mais tarde, em seu livro Communities of practice (1998), Wenger deixa claro que há diferentes formas de participação em comunidades de prática e que essas comunidades não devem ser entendidas de forma idealizada como "refúgios de união ou ilhas de intimidade" (p. 77), mas que discordâncias, desafios e competição podem ser formas de participação. Segundo ele, quase sempre "a rebelião revela um comprometimento maior com a comunidade do que a conformidade passiva” (WENGER, 1998, p. 77).

Além desses conflitos que são inerentes à própria aprendizagem dentro de comunidades de prática, há ainda aqueles que surgem a partir da participação des membres de uma comunidade em outras comunidades de prática no decorrer de suas trajetórias de vida. No caso de alunes-professores em formação inicial, estes pertencem à comunidade de prática de alunes de um curso de formação de professores e ao mesmo tempo deveriam se integrar à comunidade de prática de professores das escolas onde realizam seu estágio. Participar de diferentes comunidades de prática envolve, segundo Wenger (1998) um trabalho de reconciliação do indivíduo entre as diferentes comunidades às quais pertence. Para ele,

[o] pertencimento múltiplo pode envolver tensões contínuas que nunca são resolvidas. Mas a própria presença de tensão implica que há um esforço para manter algum tipo de coexistência. Ao usar o termo "reconciliação" para descrever esse processo de formação de identidade, quero sugerir que prosseguir com a vida - com ações e interações - implica encontrar maneiras de fazer com que nossas várias formas de pertencimento coexistam, quer o processo de reconciliação leve a resoluções bem-sucedidas ou seja uma luta constante. (WENGER, 1998, p. 160).

Dessa forma, podemos perceber que tensões e conflitos não são apenas inerentes à construção de identidade dos indivíduos e à negociação dessas identidades dentro das comunidades de prática às quais pertencem. Como exposto acima, nosso pertencimento a diferentes comunidades também implica que tenhamos que lidar com esses múltiplos pertencimentos. Argumentamos que grande parte de nossa aprendizagem e assim, de como constituímos nossa identidade, se dá exatamente em nossa capacidade de lidar com tais tensões, enfrentamentos e conflitos.

\section{Conflitos como parte inerente ao processo de desenvolvimento conceitual}

O conflito está no cerne no desenvolvimento cognitivo e profissional, é através dos questionamentos diários que es alunes-professores fazem sobre suas práticas e as práticas de outres professores que observam que eles colocam em cheque seus conceitos espontâneos, formados através da observação e das experiências vividas com os conceitos científicos apresentados deliberadamente ao longo do curso de graduação, no caso analisado Letras-Inglês.

Os conceitos espontâneos são definidos como não sistemáticos, não conscientes e comumente equivocadas (KARPOV, 2003, p. 65) enquanto que os conceitos científicos são abstratos, funcionam dentro de um sistema, são ausentes de história pessoal e iniciam com uma definição verbal (RUHMKE-RAMOS, 2018, p. 19). Assim, os conceitos espontâneos estão diretamente ligados ao que Lortie (2002) chama de “aprendizagem pela observação", que é o primeiro recurso que es alunes-professores lançam mão ao terem de lidar com situações em sala de aula. Eles buscam ancorar suas ações ao conhecimento prévio que têm 
- conhecimento este normalmente formado pelas suas experiências enquanto estudantes - e tendem a repeti-las em suas primeiras incursões no papel de professor. Lortie (2002, p. 62) nos explica que o que os estudantes aprendem sobre o Ensino é intuitivo e imitativo ao invés de explícito e analítico. Além disso, essas impressões são influenciadas e formadas com bases nas emoções que sentem e pelas suas crenças.

Neste sentido, o estágio curricular tem o papel de instigar esses alunes-professores a irem além da aprendizagem pela observação, de seu conhecimento experiencial (JOHNSON; GALOMBEK, 2011). Mas para isso, é necessário que haja agência des envolvides no processo (VYGOTSKY, 1987; JOHNSON, 2009; LANTOLF, 2003), já que o aprendizado não se dá sem esforço (VYGOTSKY, 1987).

O desenvolvimento conceitual não significa que os conceitos científicos irão substituir os conceitos espontâneos, mas sim que eles influenciarão uns aos outros no processo (VYGOTSKY, 1987), em um movimento dialético que levará tais conceitos a se transformar em um. Por exemplo, ao estudar o conceito de Língua enquanto Prática Social (GEE, 2004; JOHNSON, 2009), Ruhmke-Ramos (2018) identificou que o conceito já fazia parte do repertório des alunes-professores, em níveis diferentes de desenvolvimento conceitual entre es participantes. Ao longo do estudo, esses alunes-professores foram apresentades ao conceito científico e a exemplos de como ele poderia ser transposto em sala de aula, de forma que pudessem desenvolver suas aulas incorporando tal conceito. Ao final, observou-se que esses alunes-professores foram capazes de transformar suas práticas pedagógicas, embora por vezes sem ter consciência de o estarem fazendo.

Os argumentos apresentados acima ilustram a complexidade do desenvolvimento conceitual (DELLAGNELO; MORITZ, 2017), e a importância da agência des envolvidos (VYGOTSKY, 1987; JOHNSON, 2009; LANTOLF, 2003) no processo de tornar-se professores. Tudo isso aliado a um programa de formação de professores que promova práticas socialmente situadas adequadas ao contexto em que se encontra (PAESANI, 2012) para que es alunes-professores possam ver relevância no processo.

\section{Investigando conflitos e desestabilizações no estágio: a pesquisa qualitativa, os procedimentos de pesquisa e o contexto onde alunes-professores aprendem a profissão}

Ambos os estudos apresentados neste artigo fizeram uso de metodologias qualitativas de geração e análise de dados. Para Denzin e Lincoln (2005), a pesquisa qualitativa é "uma atividade situada que localiza o observador no mundo [...] transformando o mundo em uma série de representações” (p. 3). Por conta disso, a pesquisa qualitativa não considera que o pesquisador observa objetivamente a realidade, mas que ele co-constrói, com os participantes, entendimentos destas realidades nos locais onde elas se desenvolvem, como escolas, hospitais, prisões, encontros familiares, entre outros, procurando trazer a perspectiva e voz dos participantes em seus estudos. Nesta pesquisa, procuramos levantar e discutir os conflitos trazidos por alunes-professores em decorrência de sua inserção no estágio supervisionado de inglês no Colégio de Aplicação da UFSC.

Para o recorte dado a este artigo, Luis (2017) procura identificar situações de conflito na construção identitária de uma aluna-professora através de notas de campo de aulas ministradas por ela, entrevistas e reflexões no relatório final estágio. Interessada no desenvolvimento conceitual através da mediação entre es professores formadores e es alunes-professores, Ruhmke-Ramos (2018) analisa questões de conflito identificadas em transcrições de reuniões entre es participantes e reflexões críticas que fazem parte do relatório final de estágio. Apresentamos agora, um pouco do lugar onde tais práticas ocorrem e as pessoas que dão vida a elas. 


\section{O contexto e seus sujeitos}

O Colégio de Aplicação da UFSC onde acontece este estágio é uma escola pública federal integrada ao Centro de Ciências da Educação (CED) da Universidade Federal de Santa Catarina (UFSC). É uma escola em que a maioria de seus professores tem mestrados ou doutorados em suas áreas de atuação. Além disso, é o maior campo de estágio supervisionado do Estado de Santa Catarina, recebendo alunes-professores de diversas licenciaturas da UFSC e de outras instituições, tendo igualmente um relevante papel na extensão universitária e pesquisa em educação básica.

As disciplinas de Estágio Supervisionado I ( $7^{\text {a }}$ fase) e Estágio Supervisionado II ( $8^{\text {a }}$ fase) compõem o estágio supervisionado em inglês do curso de licenciatura em língua inglesa da UFSC investigado neste estudo (ver LUIS, 2017; RUHMKE-RAMOS, 2018) e estão sob responsabilidade de dois professores do CED ${ }^{3}$ que compartilham a tarefa de orientar ${ }^{4}$ es alunes-professores com as professoras de inglês do colégio ${ }^{5}$ (LUIS, 2017; RUHMKE-RAMOS, 2018; WIELEWICKI; RUHMKE-RAMOS, 2020).

Durante o primeiro semestre, es alunes-professores iniciam observando as aulas das professoras regentes, mas em pouco tempo começam a interagir, assessorar es estudantes e criar atividades pontuais a partir de sua observação. Para iniciar o segundo semestre, eles devem submeter proposta de intervenção fundamentada a partir do olhar etnográfico que tiveram sobre o contexto escolar e, a partir das considerações de seus orientadores, desenvolver tal proposta no segundo semestre.

Nesta pesquisa, seguimos três alunas-professoras orientadas por Vanda e Maria (na pesquisa sobre identidade profissional) e três alunes-professores orientades por Wellington e Nadia (na pesquisa sobre desenvolvimento conceitual). Embora todes es seis participantes fossem novates na profissão, os dados utilizados neste recorte (conf. Tabela 1) trazem evidências de conflitos em que após serem verbalizados (GAL'PERIN, 1992) apresentavam maiores possibilidades de transformação, uma vez que poderiam ser acessados de forma consciente pelas alunas-professoras ${ }^{6}$. A tabela abaixo mostra tal dinâmica:

Tabela 1 - Participantes de Luis (2017) e Ruhmke-Ramos (2018)

\begin{tabular}{lcc}
\hline Participantes & $\begin{array}{c}\text { Pesquisa sobre construção identitária } \\
\text { (LUIS, 2017) }\end{array}$ & $\begin{array}{c}\text { Pesquisa sobre } \\
\text { desenvolvimento conceitual } \\
\text { (RUHMKE-RAMOS, 2018) }\end{array}$ \\
\hline $\begin{array}{l}\text { Professor orientador } \\
\text { Professor supervisor }\end{array}$ & Vanda & Wellington \\
Alunes-professores & Maria & Nadia \\
$\begin{array}{l}\text { Alunas-professoras } \\
\text { apresentadas neste recorte }\end{array}$ & Márcia, Bruna e Deise & Emily, Aiden e Rebecca \\
\hline
\end{tabular}

Fonte: Elaborada pelas autoras.

Uma diferença importante entre os estudos é que em Ruhmke-Ramos (2018) a pesquisa foi originada em sua sala de aula com es alunes-professores que estagiaram em um de seus grupos enquanto que Luis (2017) estava inserida no contexto no papel de pesquisadora com uma abordagem etnográfica (ERICKSON, 1990) de conhecimento de uma nova realidade.

\footnotetext{
3. À época Wellington, de 50 anos e Vanda, de 65.

4. Oficialmente es professores do CED orientam os estágios enquanto as professoras do CA supervisionam os mesmos.

5. À época Joana, de 50 anos, Maria, de 45 anos e Nádia, de 29.

6. Os dados coletados para as pesquisas foram relatórios de 29 aulas ministradas pela professora da escola e observadas pelos alunos-professores (em um período de 20 semanas), assim como uma aula ministrada por cada aluno-professor no primeiro semestre e 14 aulas ministradas individualmente por cada um deles no segundo semestre totalizando 74 aulas. Além disso, foram analisadas as reuniões pós-aula e relatório final de estágio.

7. Embora o nome oficial para se referir aes professores da escola básica que orientam es alunes-professores seja "professor supervisor", no contexto deste estágio, consideramos as professoras de inglês do Colégio de Aplicação como igualmente orientadoras/ formadoras de professores, e não atribuímos a elas simplesmente o papel de supervisionar ou controlar a inserção des alunes-professores, de forma que em todo o texto nos referimos a essas profissionais da escola como "professoras orientadoras da escola".
} 


\section{Gerenciamento de sala de aula: conflitos vivenciados por alunas-professoras novatas em sua nova posição como professoras de inglês do ensino básico}

Nesta seção, apresentamos e discutimos os conflitos vivenciados pela aluna-professora Deise, participante da pesquisa sobre identidade profissional (LUIS, 2017) e pela aluna-professora Emily, participante da pesquisa sobre desenvolvimento conceitual (RUHMKE-RAMOS, 2018). As referidas pesquisadoras, ao se engajarem em um levantamento dos principais conflitos experienciados peles alunes-professores, perceberam que tais conflitos se relacionavam em grande parte com a dificuldade des alunes-professores em lidar com gerenciamento de sala de aula, ou seja, como criar e manter um ambiente que promova a aprendizagem e o crescimento social, emocional e moral des estudantes (WEINSTEIN; NOVODVORSKI, 2015). O objetivo de olhar para os conflitos e a partir deles identificar os temas mais relevantes para es alunes-professores vislumbra uma preocupação em trazer para o trabalho uma perspectiva êmica (PIKE, 1954) que procura capturar os significados que os participantes dão para os eventos em que estão envolvidos.

Deise

Deise vinha de uma família de classe média, tinham à época da geração de dados 23 anos e havia concluído o ensino básico em escola particular. Ela nunca havia lecionado inglês no ensino básico ou em escolas de idiomas, mas havia começado a dar algumas aulas particulares. Deise tinha escolhido o curso de Letras-Inglês por ter facilidade com a língua e por almejar tornar-se professora particular de inglês, pois havia tido uma experiência muito satisfatória de aprendizagem com uma professora particular. Ela vislumbrava um futuro profissional na profissão, inclusive trabalhando em escolas de educação básica. Deise compunha seu grupo de estágio com Márcia e Bruna, da mesma idade, que eram suas melhores amigas. Elas estavam responsáveis pela turma de $8^{\circ}$ ano da professora Maria (16 estudantes, com idades entre 12 e 13 anos). Nos dediquemos, então, aos conflitos trazidos por ela.

Deise: "Eu virei a teacher Bro, né?"

Ao entrar em contato com a turma da professora Maria, o grupo de alunas-professoras não pareceu encontrar dificuldades de integração e conseguiu construir uma identificação bastante próxima com es estudantes. Em uma entrevista com a pesquisadora no início de sua regência no Estágio Supervisionado II, Deise falou um pouco sobre sua relação com seus alunes:

Deise: Eles são legais. No começo era tipo “meu Deus, são encapetados, coitados”. Mas depois cê vai pegando carinho, né, não adianta, cê começa a ficar muito tempo com eles, agora eu virei a teacher Bro, né, que eu faço "assim" [sinaliza gesto de hang loose com a mão] pra eles [risos].

Pesquisadora: Teacher Bro, entendi.

Deise: Aí às vezes eles me chamam de teacher Bro [risos]. (Entrevista com Deise, 25 jun. 2014).

Como Deise nos conta acima, ela se tornou, para es estudantes, a teacher Bro; a palavra teacher significando professora e a palavra Bro com o sentido de "mano" ou "camarada". Deise seria então, para es estudantes, a professora "camarada", descolada, que os cumprimenta com um sinal de hang loose, uma identidade que ela parece ter desejado construir com eles e que aparentemente encontrou eco no desejo des alunes. Como vimos acima, a identidade de Deise como professora é construída na interação com a comunidade de prática à qual ela está inserida, na forma com a qual ela se vê, mas também na maneira com a qual es outres membres da comunidade (alunes, alunes-professores, professores formadores) a enxergam, 
sempre através do discurso. Gee (2000) argumenta que a identidade implica "ser reconhecido como um certo tipo de pessoa em um determinado contexto" (GEE, 2000, p. 99) e isso fica claro no excerto acima, mas também no trecho que trazemos abaixo, onde o grupo de alunas-professoras (Deise, Bruna e Marcia) decide descrever Deise da seguinte forma:

Deise é conhecida por ser a engraçadinha da turma, às vezes brincando até demais. Esse jeito moleca de ser fez com que ela se aproximasse rapidamente dos alunos, tonando-se também grande amiga dos alunos dessa e de outra turma. (Relatório final de estágio das alunas-professoras, 2014).

As alunas-professoras, junto com Deise, decidem descrevê-la como a "engraçadinha" a "moleca" e brincalhona, admitindo que tal identidade a aproximou des alunes, mas que às vezes ela pode "brincar até demais". Dessa forma, Deise parece ter construído uma identidade híbrida (BÜHRER, 2012) na interação com seus alunes, na qual as possibilidades de ser professora e amiga estão presentes, notadamente através da identidade da teacher Bro. Entretanto, à medida em que Deise começou efetivamente a ministrar suas aulas no segundo semestre do estágio, após a conclusão das aulas de sua colega Márcia, foi possível perceber gradualmente menos momentos da teacher Bro em sala, e Deise parece ter sentido a necessidade de agir com mais firmeza na aula, como mostra o excerto abaixo:

É a segunda aula de Deise na turma e parece que alguns alunes estão tentando chamar sua atenção. Eles estão muito animados e engajados com o quiz proposto pelas alunas-professoras, mas também muito barulhentos. Deise fala pra Bia [aluna] "Cê tá terrível hoje!" e Bia fica quieta. [...] Ao final da aula, Deise repreende es alunes em português, dizendo que com a professora Marcia eles respeitavam mais; que ela sabe que é quase o fim do semestre, mas que eles não são os únicos que estão cansados, também os professores estão cansados. Ela também diz que não gosta de repreendê-los, porque isso é chato para ela e para eles. Deise diz que es alunes devem respeitar mais, que não é para eles ficarem mudos nas aulas, mas para participar, respeitando os colegas e professores. Es alunos ouvem Deise em absoluto silêncio e eu noto que Bia começa a chorar discretamente. (Notas de campo, aula de inglês da Deise, 26 set. 2014).

Este excerto traz um dos primeiros momentos no qual pudemos testemunhar, como pesquisadoras, uma postura séria, aborrecida, e uma atitude firme de Deise em relação ao "mau" comportamento des alunes. Aparentemente, essa novidade na postura de Deise também é notada peles estudantes, e eles ficam mudes ouvindo, atentamente, sua reprimenda. $\mathrm{O}$ choro da estudante Bia pode ter tido alguma relação com o momento de tensão da aula, mas é também verdade que ela passava por momentos difíceis em sua vida pessoal. Mesmo assim, a mudança de atitude de Deise em relação ao gerenciamento de sala de aula pareceu ser mesmo uma história significante (SFARD; PRUSAK, 2005) na sua experiência durante o estágio, não somente para ela mas também para es estudantes, já que ressoou em outras aulas, tal como podemos ver na reflexão de Deise sobre a aula seguinte, que discutiremos na seção a seguir.

\section{"Na última aula tu nos deu uma bronca": a conversa disruptiva des alunes}

Os conflitos oriundos da dificuldade de Deise em lidar com a conversa disruptiva des alunes, ou seja, aquela conversa que atrapalha o andamento da aula, pareceram significantes na narrativa dela sobre seu estágio. Pudemos perceber isso na aula de Deise que acabamos de discutir e que reverberou em outras aulas, como mostra o excerto a seguir:

Comecei a aula cumprimentando os alunos e perguntando se eles estavam bem. Pedi para que eles me falassem o que tinha acontecido na aula anterior, para fazer uma breve recapitulação. Foi interessante ver que os alunos focaram na bronca que foi dada no final da aula. Vários deles falaram: "na última aula tu nos deu uma bronca", e eu pedi desculpa e disse que precisava conversar com eles. (Reflexão de Deise sobre sua aula, relatório final de estágio, 29 set. 2014). 
Como Deise narra neste excerto, quando ela interpela es alunes sobre o que aprenderam na aula anterior, eles rapidamente se lembram do momento da aula em que ela os repreendeu sobre seu comportamento. Parece que eles perceberam algo diferente em relação a teacher Bro, que outrora os abordava com humor, mas que mudou sua atitude naquela aula. Desde o início de sua relação com es estudantes, Deise fazia um esforço para se estabelecer como "uma igual" a eles, tão jovem e descolada quanto eles, notável no modo como se cumprimentavam, se tornando a amada teacher Bro.

Ela se sentia à vontade alinhando-se aos/as alunes, tornando-se sua “amiga” e, até a aula descrita acima, ela raramente es contrariava, procurando deixar o aprendizado o mais relaxado possível. No entanto, assim como es alunes-professores no estudo de Kanno e Stuart (2011, p. 247), ela pode ter percebido que "precisava exercer mais autoridade para conseguir um melhor gerenciamento da sala de aula" Parece que Deise estava passando por um processo de construção de sua identidade como professora, ao enfrentar conflitos em relação à sua capacidade de gerenciar seu grupo de alunes em direção a seus objetivos de ensino. Neste episódio, Deise considera es estudantes mais responsáveis pelo sucesso das aulas, vendo esse sucesso não como um reflexo direto de seu valor como professora. Parecia que ela estava começando a se sentir mais à vontade com sua identidade como professora, mas, por outro lado, isso significava que tanto ela quanto seus estudantes começavam a perceber que não eram, e talvez não pudessem ser, exatamente iguais. Ao contrário de Deise, Emily, do estudo de Ruhmke-Ramos (2018) precisou lidar com algo totalmente diferente, mas igualmente desconfortável para alunes-professores novates, o silêncio perturbador des alunes.

\section{Emily}

Emily tinha 35 anos e havia iniciado a graduação em Letras-Inglês por sua paixão pela língua, pela música e pela cinematografia. Trabalhava como revisora de textos de língua portuguesa e estágio curricular obrigatório era a primeira experiência de Emily com o ensino de inglês em uma escola pública. Nos primeiros relatos de observação era evidente sua surpresa com os acontecimentos em sala de aula (e.g., resistência des estudantes ao usar a língua alvo; relação teoria-prática; participação ativa des estudantes na tomada de decisões) e como transcrever tais situações para o relatório crítico de observação. Essas situações vivenciadas por Emily no início do estágio começam a demonstrar o conflito entre o que ela havia experienciado enquanto estudante e o que estava observando agora na posição de aluna-professora. Como estudante, ela relata que a língua inglesa parecia algo distante, seja porque suas professoras pertenciam a uma classe social mais elevada que a dela, seja por sua personalidade introvertida que, aliados ao comportamento arredio des colegas, reforçavam esse distanciamento e dificuldade em se posicionar durante as aulas ${ }^{8}$.

\section{"Tá, eles não sabem, e agora? O que eu faço?": o silêncio perturbador des alunes}

Ao iniciar o estágio e realizar sua primeira experiência de ensino ainda no primeiro semestre, Emily apresentava um plano estruturado e sabia exatamente como desenvolvê-lo. Entretanto, esta situação a levou a lidar com questões de interação em sala de aula que se mostraram mais desafiadoras que inicialmente pensado, como a apatia e falta de participação des estudantes. Ao direcionar as questões para es estudantes e não obter resposta, Emily utiliza do que chama de "instinto" para lidar com a situação e acaba por resolver as questões ela mesma.

Nadia: Como é que você acha que você incluiu ou não essas interações dos alunos [...] ao longo da tua aula?

Emily: Como que eu lidei com isso? [...] Tu sempre acha que tu vai perguntar e vai ter resposta, né?

8. Segundo Lortie (2002) escrever sobre sua trajetória pode ajudar es alunes-professores a tornar-se conscientes sobre suas escoIhas e ações enquanto professores. 
Tu espera isso, mas não aconteceu várias vezes. [...] Foi meio que instintivo assim "tá, eles não sabem e agora? O que eu faço?” Daí eu pensava na hora, né? Então assim, não foi nada planejado, eu tive que lidar na hora com o que me foi apresentado, assim, também não sei avaliar se eu fiz corretamente, se eu poderia ter feito diferente, poderia ter feito diferente, com certeza poderia, mas não sei avaliar assim mais profundamente, fui seguindo o instinto. (Reunião após primeira regência, jun. 2014, grifos nossos).

O gerenciamento da sala de aula, principalmente no tocante a interação entre estudantes-estudantes e professora-estudantes foi o conceito que mais apresentou conflitos para Emily. No excerto acima, percebemos suas dificuldades ao ter que lidar com o que chamamos de "silêncio perturbador" des estudantes em relação a suas propostas de interação. Em outra ocorrência, Emily é levada a refletir sobre tal silêncio através de diferentes possibilidades de procedimentos em sala de aula.

Wellington: Vamos pensar assim: vamos retomar o plano. Qual era a ideia do plano?

Emily: A ideia era mostrar o vídeo e [...] sobre a primeira atividade [...] aqueles primeiros statements, aquelas afirmações, a minha ideia era que eles se posicionassem sobre aquilo, né? Eles se posicionaram, eu acho que eu não soube explorar muito bem o posicionamento deles.

Wellington: Que que poderia ter feito? [...] vocês fizeram umas escapatórias assim do tipo "se eles não vêm eu vou, né?"

Emily: Uhum.

Wellington: Mas se eles não estão vindo, o que tu pode fazer, então nesse caso? Só pensando pra aproveitar melhor a discussão, o que poderia fazer?

Emily: No sentido do começo da aula?

Wellington: Do aproveitamento que eu não vi. [...] Mas ao invés de responder, será que não é uma boa estratégia largar a pergunta de volta pra eles, redistribuir a pergunta? (Reunião pós-aula, 6 jun. 2014, grifos nossos).

No excerto acima, o professor orientador procura instigar em Emily uma reflexão sobre estratégias que ela pode utilizar quando se depara com tal "silêncio perturbador" des estudantes, estratégias que vão além de simplesmente providenciar as respostas para eles. Johnson e Dellagnelo (2013) argumentam sobre o quanto tal tipo de mediação oferece oportunidades para es alunes-professores recriarem os passos da aula e refletirem sobre suas ações. Em uma discussão posterior, ao abordar explicitamente sobre a interação entre estudantes-professora, Emily relata que confiou em um estudante para conduzir sua aula.

Nadia: Como é que você acha que foi a tua interação com todos os alunos da turma hoje?

Emily: Com todos?

Nadia: Você conseguiu ouvir todos? Você conseguiu olhar pra todos? Você conseguiu observar o que cada um tava fazendo? Como é que foi isso?

Emily: Não, eu acho que eu... sei lá, em momentos diferentes, uma hora eu fiquei muito focada ali [aponta para um lado da sala] porque ali [o estudante] estava respondendo, aquela coisa, né? Quando responde se agarra neles e fica ali. [...] Mas acho que não foi muito boa, a interação, sabe? "Ah, eu olhei pra ele, está olhando pra mim, agora eu vou perguntar pra ele. Agora, que ele está prestando atenção vou perguntar pra ele”. (Reunião pós-aula, 6 out. 2014, grifos nossos).

Emily explica que não teve uma boa interação com todes, pois sua atenção estava direcionada a apenas um estudante, que além de estabelecer contato visual com ela estava sempre disposto a responder suas questões. Desta forma, ela confiou neste estudante para conduzir sua aula. Embora durante a conversa pós-aula e interações posteriores tenha sido explicitamente apontada a necessidade de envolver todes 
es estudantes no processo, a mediação não ressoou imediatamente nas aulas posteriores e ainda foi necessária a intervenção do professor formador durante uma das aulas.

Emily pergunta se os alunos entenderam as questões e eles dizem que não. Com isso professor Wellington menciona para Emily que ele acha que os alunos não entenderam o que eles têm que fazer com as questões, e que esse é o problema, não o fato de eles não entenderem as perguntas. [...] Emily então pergunta novamente, em português, se os alunos entenderam e eles explicam o que acreditam que deve ser feito. Ela confirma. (Relatório crítico de aula, relatório final, 2014, grifos nossos).

A partir da intervenção do professor, Emily entende imediatamente o que deve ser feito, parafraseando a orientação dele em português e explicando novamente, uma vez que o problema não era linguístico e sim sobre o propósito da atividade. Dessa forma, ela conseguiu contornar a situação após a mediação. A dificuldade de Emily em lidar com a participação des estudantes pode ser entendida através do argumento de Johnson e Dellagnelo (2013, p. 410) de que es noves professores normalmente imaginam suas futuras salas de aulas como centradas ne estudante em um ambiente colaborativo de aprendizagem. Neste ambiente, o professor tem um papel de facilitador e e estudante tem um papel ativo, significativo e engajado no processo. Neste excerto fica claro o conflito que ela estava vivendo, tendo que lidar com estudantes apátices e nada participatives. Tal comportamento não era o esperado por Emily com base nas atividades comunicativas que havia preparado e ela acaba por utilizar a língua materna em sala na tentativa de conseguir a atenção des estudantes.

\section{Emily: nosso papel é, antes de tudo, de educadores, e como tal devemos ser firmes em nossas decisões, mesmo que isso signifique desagradar ou contrariar um aluno}

Em um outro momento, observamos uma mudança nas ações de Emily com relação ao gerenciamento de sala de aula, e para além da questão do foco individualizado observamos sua dificuldade em se manter firme na tomada de decisões em sala de aula, a partir da resistência des estudantes sobre as mesmas. No exemplo, ela havia inicialmente definido que os grupos para o projeto final seriam organizados via sorteio, mas no decorrer da aula, como vários chegaram atrasados, ela muda a orientação para que eles se organizem e depois, quando da chegada dos estudantes restantes, ela tenta retomar a orientação inicial. Comentários de Emily:

Quero destacar a importância de ter firmeza nas decisões e não se deixar influenciar (pelo menos não sempre) pelas reclamações dos alunos [...]. Essa situação me fez refletir sobre como nós professores, temos que ter consciência de que nosso papel é, antes de tudo, de educadores, e como tal devemos ser firmes em nossas decisões mesmo que isso signifique desagradar ou contrariar um aluno. Percebi que essa não é uma função fácil, pois, é muito mais cômodo você ceder à "pressão" [...]. (Relatório crítico de aula, relatório final, 2014, grifos nossos).

As reclamações des estudantes levaram Emily a refletir sobre o papel educacional do professor e da dificuldade deste em manter seu posicionamento e não se deixar ser manipulado por eles. Por ser professora novata, ela sente a necessidade de agradar es estudantes, não entrar em conflito com eles. E por isso, acaba por fazer concessões que por vezes prejudica o objetivo estabelecido por ela para a aula.

As ações de Emily podem ter sido muito influenciadas pela ansiedade que atrasa o aprendizado. Segundo Lortie (2002), alguns/algumas professores iniciantes terão dificuldade na percepção e na tomada de decisões bem pensadas na medida em que aprendem o trabalho por conta da ansiedade (p. 72). Entretanto, observamos que embora houvesse muito barulho na turma, a forma como Emily conduziu a aula demonstra mudanças em seu comportamento. 
Emily: É, eu tinha planejado dar o tempo pra eles fazerem a atividade, pra eles discutirem em grupo pra depois a gente... Né... Eu pulei um monte de coisa, eu extrapolei assim, não fiz a sequência nada que eu tinha planejado. Na verdade...

Nadia: Mas, por outro lado, eu te sinto bem mais à vontade.

Emily: Uhum.

Nadia: Né? Você já transita muito melhor assim, você estava confiante das coisas que você tava fazendo. Você tinha estudado, você tinha se preparado. Então, por isso que você pulou, mas você estava sabendo. Você não pulou, por exemplo, por não saber, por insegurança. Você pulou porque você achou que era o que tinha que ser feito naquele momento [...]. (Reunião pós-aula, 1 nov. 2014, grifos nossos).

A dificuldade de Emily é esperada, uma vez que a aprendizagem se dá em espiral (VYGOTSKY, 1995), e em algumas aulas a interação foi melhor do que outras e esse processo continuará com altos e baixos até que ela tenha conseguido modificar alguns procedimentos e posturas em sala de aula com aquela turma. Outras turmas, irão demandar novas adaptações, interações sociais e assim será sucessivamente (OLIVEIRA, 1999). O primeiro passo que é o reconhecimento das dificuldades através da verbalização (GAL'PERIN, 1992) foi dado e assim possibilitará mudanças em seu desenvolvimento e internalização que levará tempo e engajamento para que as ações sejam transformadas. Não queremos defender o argumento que o sucesso ou não de uma aula depende da postura do professor e sim que as aulas são adaptadas de acordo com o perfil da turma, entendemos que para que as aulas sejam proveitosas é necessário o engajamento de todes es envolvides no processo.

Foram identificadas dissonâncias emocionais e cognitivas na prática de Emily. Entretanto, ela estava constantemente saindo de sua zona de conforto conforme identificado na diferença de planejamento e execução das aulas. Emily trabalhou desconfortavelmente em seu ZPD ${ }^{9}$ (CHILDS, 2011) na medida em que a mediação ocorria e ela era questionada sobre suas ações que a levava a reflexão. Neste sentido, a prática desencadeou um processo nada sutil e agradável ao lidar com funções cognitivas instáveis de maturação de seu ZPD (JOHNSON; GOLOMBEK, 2011, p. 13). Emily estava determinada a aprender, o que é uma condição sine qua non para que o desenvolvimento conceitual ocorra (SMAGORINSKY; COOK; JOHNSON, 2003).

O estágio da Emily foi desafiador para ela pois a levou a lidar com inúmeras questões que estão além do planejamento metodológico e linguístico. Emily procurou ao longo do estágio mediação para lidar com os desafios encontrados, já que o planejamento foi transposto em aulas de forma diferente do que foi elaborado originalmente. Seus conflitos demonstraram quão desafiador e cheio de esforço o processo de aprendizagem pode ser. Exemplos estes que reforçam o argumento de Vygotsky de que não há aprendizagem sem engajamento (VYGOTSKY, 1987, p. 176). E esse engajamento fica evidenciado em seu esforço e determinação em superar algumas características como a timidez, e o aprendizado pela observação conforme discutido nas ocorrências relatadas acima.

\section{Barulho disruptivo vs. silêncio perturbador: aprendendo a ser professor através de conflitos}

Ambas as pesquisas de Luis (2017) e Ruhmke-Ramos (2018) revelaram que o conflito em si é uma constante nas experiências e interpretações des alunes-professores durante o estágio, algo que foi possível perceber através da perspectiva êmica deste estudo, ou seja, do olhar de duas pesquisadoras sobre seus dados de pesquisa em relação à aprendizagem em pré-serviço de professores de inglês. Enquanto Deise encontrou dificuldades em relação ao barulho disruptivo de seus estudantes do $8^{\circ}$ ano, Emily precisou lidar

9. ZPD refere-se à zona de desenvolvimento proximal (VYGOTSKY, 1978). De forma simplificada, este conceito indica o espaço em que um indivíduo está quando está aprendendo algo novo. Esse conhecimento novo deve ser mais complexo do que o conhecimento já adquirido e precisa de mediação para ser atingido, mas ao mesmo tempo deve estar minimamente ancorado à zona de desenvolvimento real do indivíduo para que o desenvolvimento aconteça. 
com o silêncio perturbador de seus alunes do $1^{\circ}$ ano do Ensino Médio. Foi possível perceber que muitas das dificuldades vivenciadas e relatadas por elas se relacionavam a questões de gerenciamento da sala de aula e das interações que ocorrem nesse ambiente, aspectos que muitas vezes são negligenciados em cursos de formação de professores por aparentarem ser de natureza puramente técnica, o que discordamos.

Da mesma forma, parecia existir entre as alunas-professoras destes estudos um desejo comum de não contrariar es alunes, de agradá-les e incomodá-les o mínimo possível, muitas vezes fazendo com que desviassem dos objetivos educacionais que elas mesmo haviam traçado para suas aulas. Sendo assim, elas tiveram que enfrentar conflitos que surgiam em sala quando seus objetivos estavam em desacordo com a vontade des alunes naquele momento. Entretanto, as pesquisas mostraram que elas conseguiram refletir sobre seus papéis e suas identidades como professoras ao serem confrontadas por situações desse tipo, um passo inicial muito importante em suas trajetórias de aprendizagem docente.

Após a conclusão de seus estágios, as alunas-professoras relataram aprendizagem significativa a partir da vivência intensa e extensa neste ambiente. No comentário de Emily, abaixo, identificamos aprendizagem através de sua percepção da complexidade do fazer docente:

Tu tem uma visão muito superficial até tu ter a experiência, até porque sentar, planejar uma aula, como tu vai conduzir aquela aula, o que que tu vai enfatizar, o que tu pode deixar de lado, o que é relevante pro aluno, o que que não é, de que forma tu vai apresentar aquilo interessante pro aluno, sabe? (Reunião final de estágio, 9 dez. 2014).

As observações apontadas por Emily nesse trecho sugerem um amadurecimento e desenvolvimento profissional. Identificamos em sua verbalização a consciência sobre os desafios enfrentados por ela no estágio, o que indica que dentro do processo dinâmico de desenvolvimento conceitual há muito espaço para crescimento. Entendemos que o conceito de gerenciamento de sala de aula pode repentinamente fazer sentido para Emily em um futuro próximo na medida em que ela assume suas próprias salas de aula. Ayers (2003, p. 15) resume bem esse processo dizendo que o aprendizado é dinâmico e explosivo e que boa parte dele é informação, que se constrói ao longo do tempo e se conecta subitamente. Enquanto Emily relata ter conseguido adquirir uma visão mais holística sobre o trabalho docente, Deise relata ter transformado sua identidade como professora, como vemos abaixo:

A matéria que eu mais aprendi coisa com certeza foi o estágio, sabe. Mas é cansativo e te deixa um pouco maluca [risos] [...]. Eu acho que antes [do estágio] eu simplesmente dava aula, fechava o livro e ia embora. E agora eu penso tipo “ã, mas por quê que eu fiz isso quando eu tava dando aula?", sabe? Cê começa... eu acho que eu aprendi a refletir o que eu faço, e o que eu vou fazer, por que eu fiz, por quê que eu vou fazer as coisas [...]. Cê começa a refletir de tudo na sua vida [risos] [...]. Cê leva isso pra vida né, cê fica... acho que cê fica muito mais crítica das coisas que acontecem em volta de você. (Entrevista com Deise, 10 ago. 2015, grifos nossos).

Em seu relato acima, Deise afirma ter sido o estágio a disciplina onde sentiu uma aprendizagem mais significativa, provavelmente por estar aprendendo na prática, através de seu engajamento em uma comunidade de professores (WENGER, 1998). Os conflitos advindos da participação ativa de Deise no estágio a fizeram perceber, como relatamos neste artigo, que ela precisava exercer mais autoridade em sala para conseguir um melhor gerenciamento da turma. Para além deste aspecto, neste relato final, ela argumenta que tal experiência transformou sua identidade profissional, de uma professora acrítica para uma professora crítica e reflexiva, extrapolando os limites da sala de aula, para inserir-se em sua vida cotidiana.

Como Wenger (1998) sugere, a aprendizagem como atividade situada em comunidades de prática é uma experiência de identidade porque "pode transformar quem somos e o que podemos fazer" (p. 215). Sfard e Prusak (2005) parecem concordar com Wenger (1998) sobre a capacidade que uma aprendizagem significativa tem em mudar a história de uma pessoa, ou seja, em transformar sua identidade. Dessa forma, a intensidade do engajamento de Deise no estágio a fez enfrentar conflitos surgidos a partir 
de sua posição híbrida (BÜHRER, 2012) como aluna de um curso de formação e professores e professora des estudantes da escola. Porém, argumentamos que tais desestabilizações e dificuldades foram cruciais para que ela percebesse tamanha aprendizagem e transformasse sua identidade profissional.

\section{Considerações finais}

Buscamos neste trabalho discutir dados de duas pesquisas qualitativas na área de formação de professores de inglês que, embora tenham sido conduzidas por diferentes perspectivas: perspectiva sociocultural e (re)construção de identidades, trazem questões comuns a ambos os estudos. Ambas as pesquisas identificaram nos conflitos oportunidades de desenvolvimento conceitual e transformação identitária dos participantes, inseridos em comunidades de prática de professores. Dessa forma, os conflitos não têm caráter limitador, mas demonstraram ser essenciais na aprendizagem prática das alunas-professoras.

Pudemos observar que a maioria dos conflitos enfrentados pelas alunas-professoras se relacionavam ao gerenciamento de sala de aula, no caso de Deise pelo barulho disruptivo des estudantes e Emily pelo silêncio perturbador deles. Em ambos os casos, percebemos o desejo das alunas-professoras em agradar es estudantes, o que por vezes dificultava que elas atingissem os objetivos estabelecidos por elas mesmas para suas aulas. Tais situações sinalizam o processo de desestabilização de conceitos sobre o ensino/aprendizagem de línguas e de (re)construção de identidades profissionais pelos quais elas passavam.

Através da identificação desses conflitos, pudemos ter uma melhor compreensão de como as áreas afins poderiam contribuir para a análise e interpretação dos dados uma vez que eles não só se complementam como se retroalimentam. Defendemos assim, o argumento de que o diálogo entre as áreas pode contribuir para o desenvolvimento de pesquisas mais robustas que oferecem um cenário mais amplo para análise do objeto/problema/questão/situação/contexto.

\section{Referências}

AYERS, William. To Teach: the journey of a teacher. New York: Teachers College Press, 2003.

BÜHRER, Édina Aparecida Cabral. Identidade e hibridismo: discutindo a condição de aluno-professor no estágio supervisionado em língua inglesa. 2012. 223 f. Tese (Doutorado em Letras) - Universidade Federal do Paraná, Curitiba, 2012.

CHILDS, Sharon S. 'Seeing' L2 Teacher Learning: the power of context on Conceptualizing Teaching. In: GOLOMBEK, Paula; JOHNSON, Karen (ed.). Research on second language teacher education: a sociocultural perspective on professional development. Abingdon: Routledge, 2011. p. 108-132.

DELLAGNELO, Adriana Kuerten; MORITZ, Maria Ester Wollstein. Mediação e (res)ignificação docente: a repercussão na prática pedagógica. In: HEBERLE, Viviane; TOMITCH, Lêda Maria Braga (ed.). Perspectivas atuais de aprendizagem e ensino de línguas. Florianópolis: LLE/CCE/UFSC, 2017.

DENZIN, Norman; LINCOLN, Yvonna. Introduction: The discipline and practice of qualitative research. In: DENZIN, Norman; LINCOLN, Yvonna (ed.). The SAGE handbook of qualitative research. 3. ed. Thousand Oaks: Sage Publications, 2005. p. 1-32.

ERICKSON, Frederick. Qualitative methods. In: LINN, Robert; ERICKSON, Frederick (ed.). Quantitative methods, qualitative methods. 1. ed. New York: Macmillan Publishing Company, 1990. v. 2. p. 77-200.

GAL'PERIN, Pyotr Yakovlevich. Linguistic consciousness and some questions of the relationships between language and thought. Journal of Russian and East European Psychology, United States, v. 30, n. 4, p. 28-49, 1992.

GEE, James Paul. Identity as an analytic lens for research in education. Review of Research in Education, United States, v. 25. p. 99-125, 2000.

GEE, James Paul. Learning language as a matter of learning social languages within discourses. In: HAWKINS, Margaret (ed.). Language learning and teacher education: a sociocultural approach. Clevedon, UK: Multilingual Matters, 2004. p. 13-31. 
HANDLEY, Karen; STURDY, Andrew; FINCHAM, Robin; CLARK, Timothy. Within and Beyond Communities of Practice: making sense of learning through participation, identity and practice. Journal of Management Studies, United Kingdom, v. 43, n. 3, p. 641-653, 2006.

JOHNSON, Karen. Second Language Teacher Education: a Sociocultural Perspective. New York: Routledge, 2009.

JOHNSON, Karen; DELLAGNELO, Adriana Kuerten. How 'sign meaning develops': Strategic mediation in learning to teach. Language Teaching Research, United States, v. 17, n. 4, p. 409-432, 2013.

JOHNSON, Karen; GOLOMBEK, Paula. A Sociocultural Theoretical Perspective on Teacher Professional Development. In: JOHNSON, Karen; GOLOMBEK, Paula (ed.). Research on second language teacher education: sociocultural perspective on professional development. Abingdon: Routledge, 2011. p. 1-12.

KANNO, Yasuko; STUART, Christian. Learning to become a second language teacher: identities in practice. The Modern Language Journal, United States, v. 95, p. 236-252, 2011.

KARPOV, Yuriy. Vygotsky's Doctrine of Scientific Concepts. In: KOZULIN, Alex et al. (ed.). Vygotsky's Educational Theory in Cultural Context. Cambridge, UK: Cambridge University Press, 2003.

LANTOLF, James. Intrapersonal Communication and Internalization in the Second Language Classroom. In: KOZULIN, Alex et al. (ed.). Vygotsky's Educational Theory in Cultural Context. Cambridge, UK: Cambridge University Press, 2003. p. 349-370.

LAVE, Jean; WENGER, Etienne. Situated learning: legitimate peripheral participation. Cambridge, UK: Cambridge University Press, 1991.

LORTIE, Dan. Schoolteacher: A Sociological Study. London: University of Chicago Press, 2002.

LUCENA, Maria Inêz Probst; SILVA, Marimar da; BAZZO, Vera Lúcia. Se não pudermos fazer o melhor aqui, não poderemos fazê-lo em nenhum outro lugar - Memórias de professores-formadores sobre o estágio curricular desenvolvido no CA/UFSC na última década. In: DIAS, Maria de Fátima Sabino et al. (org.). História, Memórias e Práticas Escolares. 1. ed. Florianópolis: Letras Contemporâneas, 2014. v. 1. p. 124-144.

LUIS, Renata Gomes. The process of professional identity construction of student-teachers of English during the student teaching. 472 f. 2017. Tese (Doutorado em Estudos da Linguagem) - Universidade Federal de Santa Catarina, Florianópolis, 2017.

OLIVEIRA, Marta Kohl de. Organização Conceitual e Escolarização. In: OLIVEIRA, Marcos Barbosa de; OLIVEIRA, Marta Kohl de (org.). Investigações Cognitivas: Conceitos, Linguagem e Cultura. Porto Alegre: Artes Médicas, 1999.

PAESANI, Kate. A Sociocultural Approach to Collegiate Foreign Language Teacher Professionalization: Lesson Planning and Concept Development. In: SONESON, Daniel; TARONE, Elaine (org.). Expanding Our Horizons: Language Teacher Education in the 21st Century. Minneapolis: CARLA - University of Minnesota, 2012.

PIKE, Kenneth Lee. Language in relation to a Unified Theory of the Structure of Human Behavior. Dallas: Summer Institute of Linguistics, 1954.

RUHMKE-RAMOS, Nadia Karina. Practice teaching as a tool to promote concept development: a sociocultural study. 2018. 264 f. Tese (Doutorado em Estudos da Linguagem) - Universidade Federal de Santa Catarina, Florianópolis, 2018.

SFARD, Anna; PRUSAK, Anna. Telling identities: In search of an analytic tool for investigating learning as a culturally shaped activity. Educational Researcher, United States, v. 34, n. 4, p. 14-22, 2005.

SMAGORINSKY, Peter; COOK, Leslie Susan; JOHNSON, Tara Star. The twisting path of concept development in learning to teach. Teachers College Record, United Kingdom, v. 105, n. 8, p. 1399-1436, 2003.

VYGOTSKY, Lev Semionovitch. Obras escogidas III: génesis de las funciones psíquicas superiores. Madrid: Visor Distribuiciones, 1995.

VYGOTSKY, Lev Semionovitch. Problems of general psychology, and thinking and speech. In: RIEBER, Robert; CARTON, Aaron (ed.). The collected works of L. S. Vygotsky. New York: Plenum, 1987. v. 1.

VYGOTSKY, Lev Semionovitch. Mind in Society: The Development of Higher Psychological Processes. Edited and translated by Michael Cole et al. Cambridge, MA: Harvard University Press, 1978.

WEINSTEIN, Carol Simon; NOVODVORSKI, Ingrid. Gestão da sala de aula: lições da pesquisa e da prática para trabalhar com adolescentes. Porto Alegre: AMGH, 2015.

WENGER, Étienne. Communities of practice: learning, meaning, and identity. Cambridge, UK: Cambridge University Press, 1998. 
WIELEWICKI, Hamilton de Godoy; RUHMKE-RAMOS, Nadia Karina. Construção de uma Relação Orgânica e Simétrica entre Universidade e Escola: insights a partir da parceria no estágio curricular supervisionado em inglês no Colégio de Aplicação da UFSC. In: SOUZA, Alba Regina Battisti de et al. (org.). Anos Iniciais do Ensino Fundamental: Estágio Curricular e Formação Docente. Florianópolis: Insular, 2020.

Data de submissão: 19/06/2020

Data de aceite: 20/07/2020 